\title{
Intelligent Software System for Optimizing Adaptive Control of Investment Projecting Processes
}

\author{
A. F. Shorikov ${ }^{1, a)}$, E. V. Butsenko ${ }^{2, b)}$ and V. A. Tyulyukin ${ }^{2, c)}$ \\ ${ }^{1}$ Ural Federal University, Ekaterinburg, Russia \\ ${ }^{2}$ Ural State University of Economics, Ekaterinburg, Russia \\ a)afshorikov@mail.ru

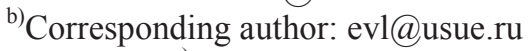 \\ c)tul@mail.ru
}

\begin{abstract}
The article describes the functionality developed by the authors of an intelligent computer software system for optimizing adaptive control of investment projecting processes in the face of uncertainty. The results of the work are based on a new method of network formalization and optimization of adaptive project control using network economic and mathematical modeling and principles of adaptive control. The developed intelligent computer program system is projecting to automate the modeling of investment projecting processes and optimize adaptive decision-making control during their implementation on the basis of network economic and mathematical modeling, as well as methods and tools for developing intelligent software systems. This system takes into account the existing specific technical and economic conditions and information support. The basis of the developed intelligent computer software system is the use of a new method of network formalization and of adaptive project control optimization, modernized to solve the problems of investment projecting. The results obtained in this work can serve as the basis for creating intelligent instrumental systems for supporting managerial decision-making in the implementation of investment projecting processes in the context of information uncertainty and risks.
\end{abstract}

\section{INTRODUCTION}

Successful activity of any enterprise requires the creation of modern tools to optimize the control of the implementation of investment projecting processes that are consistent with the initial investment project, taking into account the existing technical, economic and informational conditions, as well as emerging real production or organizational situations. To solve this problem, we propose a technology for the development and creation of an intelligent computer program system for optimizing adaptive control of investment projecting processes, based on a new method of network formalization and of adaptive project control optimization, which was developed by A.F.Shorikov and described in [1], models and methods of network economic and mathematical modeling [3-5], principles of adaptive control [2] and technology for developing intelligent systems in the form of computer expert decision support systems [2,6-11]. To formalize knowledge in this system, production logical rules are used, algorithms in the form of the implementation of finite sets of arithmetic and logical operations that establish relationships between different types of data, stereotypical situations and facts in order to obtain logical conclusions and generate results. When operating such systems, it is possible to carry out training and accumulation of formalized and non-formalized information for use in subsequent processes of inference and solving functional tasks.

\section{RESEARCH TECHNIQUE}

The proposed intelligent computer software system is developed using the technology of computer expert decision support systems [3,6,7]. It includes the following subsystems: a database containing data in various formats, structured in accordance with the system architecture and functional tasks; a knowledge base containing

Application of Mathematics in Technical and Natural Sciences

AIP Conf. Proc. 2302, 060014-1-060014-13; https://doi.org/10.1063/5.0033499

Published by AIP Publishing. 978-0-7354-4036-4/\$30.00 
facts and knowledge about models and methods of investment projecting, which are structured and formalized by various means; knowledge acquisition subsystem using various tools; a subsystem for the formation of solutions to the functional problems of the system (task solver), based on the implementation of various mechanisms using logical inference procedures, formal algorithms and heuristic procedures associated with the database and knowledge base; a subsystem of explanations (logging) of the conclusion of decisions; learning subsystem and intelligent user interface. Figure 1 shows the structural diagram of the developed intelligent computer program system containing the main subsystems.

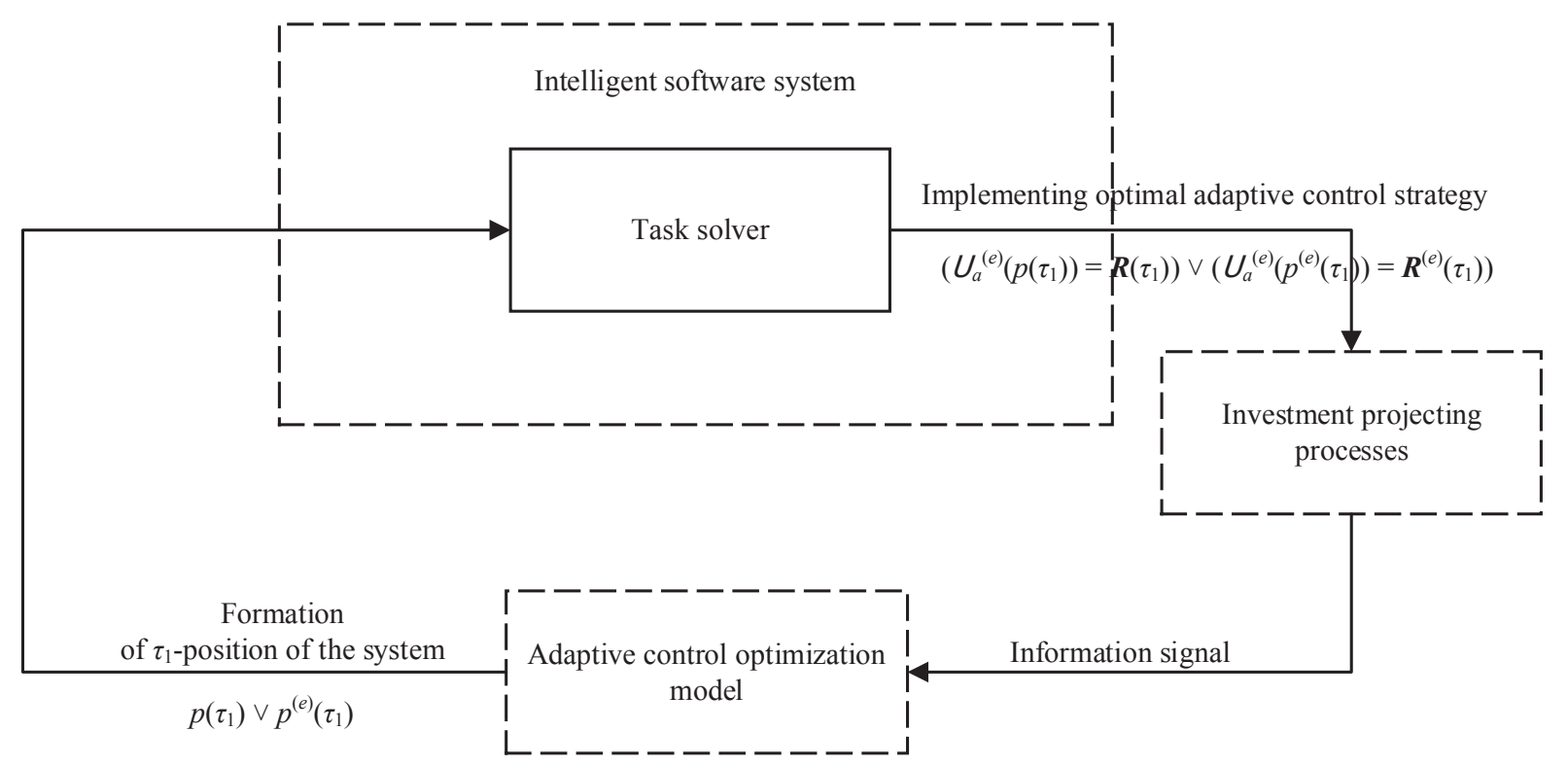

FIGURE 1. Structure of intelligent computer software system

The basis of the developed intellectual computer software system is the use of a new method of network formalization and of adaptive project control optimization [1], modernized for to solve the problems of investment projecting.

The general methodology of network planning and control of investment projecting processes for an economic entity (without the possibility of adaptation) is given in the monograph [3]. A new method of network formalization and optimization of adaptive project control, which is based on network modeling and the principles of adaptive control, is described in [1]. In this work, on the basis of this method, we developed a methodology for solving the problem of optimizing adaptive control of investment projecting processes, which is implemented in the proposed intelligent computer software decision support system in a block containing an adaptive control optimization model (Figure 1).

The task solver in the intellectual computer program system developed by the authors contains the following main blocks projecting to form: 1) a network economic-mathematical model for the implementation of investment projecting processes; 2) critical path and critical time; 3) the position of the system that describes the state of investment projecting processes; 4) the optimal adaptive strategy for managing the processes of investment projecting; 5) the final results of solving the problem of optimizing adaptive control of investment projecting processes in formats convenient for users.

\section{RESULTS}

Consider a methodology for optimizing adaptive control of investment projecting processes, which forms the basis for decision-making in the developed intelligent computer software system, using the investment project to open a cafeconfectionery with the introduction of a production line for the manufacture of confectionery as an example. It should be noted that the confectionery business has been and remains promising for small businesses, and until recently, the confectionery market has seen steady growth in their production.

The aim of the project to create a cafe-confectionery is to organize its own production and sale of confectionery in a city with a population of more than 500 thousand people and profit. The confectionery shop with a cafe-confectionery 
is planned to be placed in a room with a total area of $100 \mathrm{~m}^{2}$. The concept of the project provides for the production of confectionery products according to their own recipes and their implementation to consumers in finished form and on order. Since the cafe-confectionery will be located directly during production, the consumer is always entitled to count on the purchase of fresh produce. The assortment of the confectionery will consist of flour cakes and pastries with a total assortment of more than 110 types. Due to the not very favorable market conditions, emphasis will be placed on inexpensive products and original recipes.

To place the cafe-confectionery, the premises previously used as a cafe will be used, in connection with which there is no need to summarize the main communications. Nevertheless, it is required to repair the guest hall and the facade of the building to create the corporate identity of the cafe-confectionery.

The technological process for the preparation of confectionery depends on the specific recipe. In general, it can be divided into 5 main stages: preparation of the product for kneading dough, kneading dough, semi-finished baking, cream preparation, product projecting. The technological process for the production of confectionery products is presented in Figure 2.

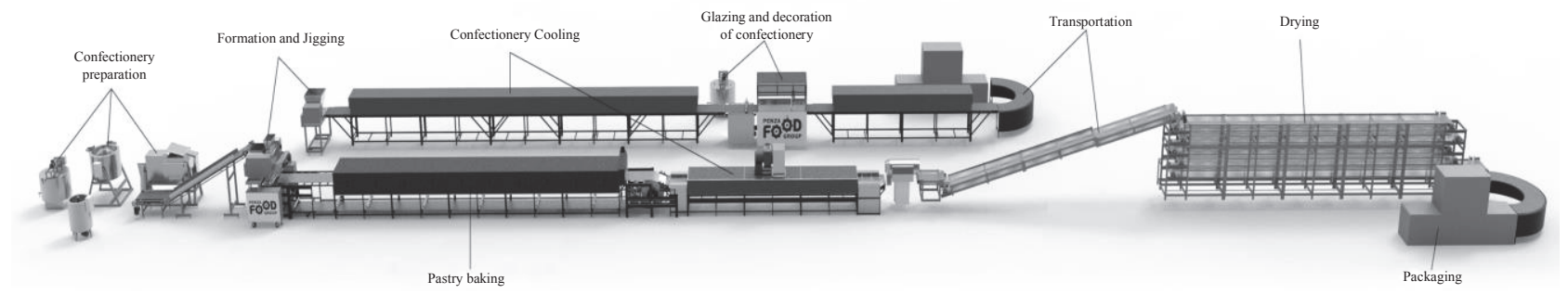

FIGURE 2. Confectionery production process

The initial information for constructing a network economic and mathematical model in the form of the main workoperations necessary for the implementation of the investment project under consideration is presented in Table 1.

TABLE 1. Initial data of the investment project

\begin{tabular}{llcc}
\hline Work & \multicolumn{1}{c}{ Content of work } & $\begin{array}{c}\text { Duration of } \\
\text { work, weeks }\end{array}$ & Previous work \\
\hline$R_{1}(0)$ & Market research and project definition & $\Delta_{1}(0)=2$ & - \\
$R_{2}(0)$ & Registration and paperwork & $\Delta_{2}(0)=4$ & - \\
$R_{3}(0)$ & Repair and projecting of the room & $\Delta_{3}(0)=2$ & $R_{1}(0)$ \\
$R_{4}(0)$ & Front works & $\Delta_{4}(0)=2$ & $R_{3}(0)$ \\
$R_{5}(0)$ & Purchase of equipment for the workshop and guest hall & $\Delta_{5}(0)=2$ & $R_{1}(0)$ \\
$R_{6}(0)$ & Installation and installation of equipment & $\Delta_{6}(0)=2$ & $R_{5}(0)$ \\
$R_{7}(0)$ & Formation of the range of products & $\Delta_{7}(0)=1$ & $R_{1}(0)$ \\
$R_{8}(0)$ & Sales Plan and Marketing & $\Delta_{8}(0)=1$ & $R_{1}(0), R_{7}(0)$ \\
$R_{9}(0)$ & Advertising & $\Delta_{9}(0)=1$ & $R_{8}(0)$ \\
$R_{10}(0)$ & Confectionery workshop production plan & $\Delta_{10}(0)=1$ & $R_{5}(0)$ \\
$R_{11}(0)$ & Organizational plan (staffing and payroll) & $\Delta_{11}(0)=1$ & $R_{10}(0)$ \\
$R_{12}(0)$ & Contracts with suppliers & $\Delta_{12}(0)=1$ & $R_{8}(0), R_{10}(0)$ \\
$R_{13}(0)$ & Financial plan & $\Delta_{13}(0)=1$ & $R_{8}(0), R_{10}(0), R_{11}(0)$ \\
$R_{14}(0)$ & Efficiency mark & $\Delta_{14}(0)=1$ & $R_{13}(0)$ \\
$R_{15}(0)$ & Risk assessment & $\Delta_{15}(0)=1$ & $R_{13}(0)$ \\
\hline
\end{tabular}

It is assumed that all the processes of investment projecting as a whole can be described as a finite set of work operations, ordered by time, taking into account the existing technological and technical and economic conditions. It is required to optimize the implementation time of investment projecting processes as a whole, using the feedback control capabilities based on monitoring the implementation of the current state of their implementation.

Then, on the basis of the available initial data and conditions, a network economic-mathematical model is formed [3-5] for the implementation of investment projecting processes in the form of a network diagram, which is shown in Figure 3. The starting event in this network is the event number 1, the final event is the event number 13.

Symbols $F_{i}(0), i \in 1,5=\{1,2, \ldots, 5\}$ indicate fictitious work that does not require time and resources for their execution.

In accordance with the new method of network formalization and of adaptive project control optimization [1], a methodology has been developed for optimizing adaptive control of investment projecting processes, which implements the execution of the initial investment project in the optimal (minimum) time. 
At the first stage, auxiliary parameters $\tau:=0, s:=0$, and on the basis of the initial data on the investment projecting processes under consideration and the rules of network economic and mathematical modeling $[3,4]$, the corresponding network model for the implementation of investment projecting processes $\boldsymbol{W M}_{\tau}^{(e)}(\boldsymbol{R}(\tau))=$ $=\boldsymbol{W} \boldsymbol{M}_{0}^{(e)}(\boldsymbol{R}(0)) \in \boldsymbol{W} \boldsymbol{M}_{0}(\boldsymbol{R}(0))$ is formed, where $\boldsymbol{W M}_{0}(\boldsymbol{R}(0))$ is the set of all valid network models in the form of a network graphics, which is shown in Figure 3 and corresponds to the array of work-operations $\boldsymbol{R}(\tau)=\left\{R_{1}(\tau), R_{2}(\tau), \ldots, R_{n_{\tau}}(\tau)\right\}=\boldsymbol{R}_{\tau}=R(0)=\left\{R_{1}(0), R_{2}(0), \ldots, R_{15}(0)\right\}=\boldsymbol{R}_{0}$, as well as the array of the duration of the execution of work-operations $\Delta(\tau)=\left\{\Delta_{1}(\tau), \Delta_{2}(\tau), \ldots, \Delta_{n_{\tau}}(\tau)\right\}=\Delta_{\tau}=\Delta(0)=$ $=\left\{\Delta_{1}(0), \Delta_{2}(0), \ldots, \Delta_{15}(0)\right\}=\Delta_{0}$, where $n_{\tau}=15$.

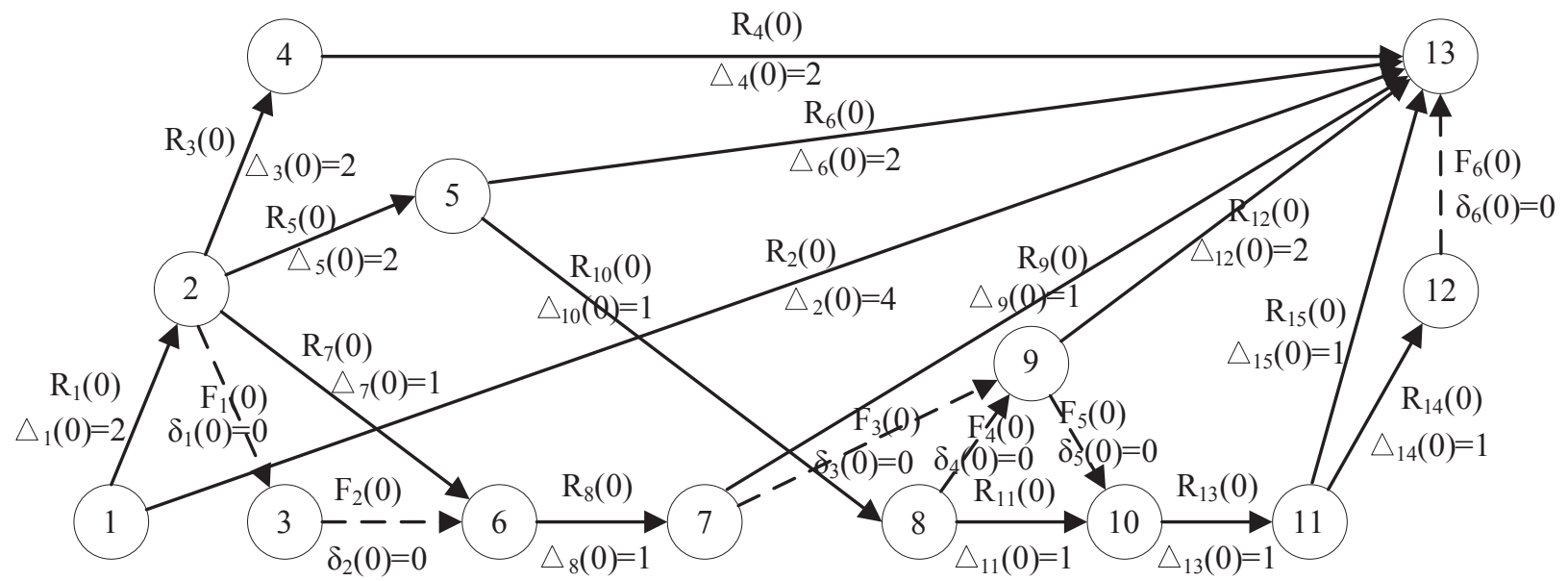

FIGURE 3. Network model for implementation of investment projecting processes $(\tau=0)$

At the second stage, based on the initial data, including - the initial array of work-operations $\boldsymbol{R}(\tau)=\left\{R_{1}(\tau), R_{2}(\tau), \ldots, R_{n_{\tau}}(\tau)\right\}=\boldsymbol{R}_{\tau}=R(0)=\left\{R_{1}(0), R_{2}(0), \ldots, R_{15}(0)\right\}=\boldsymbol{R}_{0}$, the corresponding array of the duration of the work-operations $\Delta(\tau)=\left\{\Delta_{1}(\tau), \Delta_{2}(\tau), \ldots, \Delta_{n_{\tau}}(\tau)\right\}=\Delta_{\tau}=\Delta(0)=\left\{\Delta_{1}(0), \Delta_{2}(0), \ldots, \Delta_{15}(0)\right\}=\Delta_{0}$, as well as the generated network model for the implementation of investment projecting processes, it is necessary to optimize the network model by the time parameter - find the critical path, critical time and create an appropriate calendar schedule for the implementation of investment projecting processes as a whole, i.e. solve the task of scheduling [3-5].

Formulas for calculating the time parameters of the events of the formed network model are described, for example, in [3-5]. For this network model corresponding to the considered processes of investment projecting, there are two critical paths, which are presented in Figure 4 and are highlighted in gray and in bold, with each of them having a duration of 8 weeks. To perform further actions, any of these critical paths is selected, and specifically, we select the path that consists of a set of work-operations: $\left\{R_{1}(\tau), R_{5}(\tau), R_{10}(\tau), R_{11}(\tau), R_{13}(\tau), R_{15}(\tau)\right\}=$ $=\left\{R_{1}(0), R_{5}(0), \quad R_{10}(0), R_{11}(0), R_{13}(0), R_{15}(0)\right\}$. As a result, a critical path $\boldsymbol{R}^{(k p .)}(\tau)=\left\{R_{1}^{(\kappa p .)}\left(\tau ; \tau_{1}\right)\right.$, $\left.R_{2}^{(\kappa p .)}\left(\tau_{1} ; \tau_{2}\right), \ldots, R_{n_{\tau}^{(\kappa p .)}}^{(\kappa p .)}\left(\tau_{n_{\tau}^{(\kappa p .)}-1} ; \tau_{n_{\tau}^{(\kappa p .)}}\right)\right\}=\boldsymbol{R}_{\tau}^{(\kappa p .)}=\left\{R_{1}^{(k p .)}(0 ; 2), R_{2}^{(\kappa p .)}(2 ; 4), R_{3}^{(\kappa p .)}(4 ; 5), R_{4}^{(\kappa p .)}(5 ; 6), R_{5}^{(\kappa p .)}(6 ; 7)\right.$, $\left.R_{6}^{(\kappa p .)}(7 ; 8)\right\}=\boldsymbol{R}^{(\kappa p .)}(0)=\boldsymbol{R}_{0}^{(\kappa p .)}$ is formed, where $n_{\tau}^{(\kappa p .)}=6$. The duration of the implementation of the generated critical path $\boldsymbol{R}_{\tau}^{(k p .)}=\boldsymbol{R}_{0}^{(k p .)}$ determines the critical time $T_{\tau}^{(e)}=T_{0}^{(e)}=8$, i.e., the minimum time required to complete all operations, forming the whole complex of measures for the implementation of investment projecting processes as a whole. Next, an integer array of time periods is formed for the implementation of the optimization of 
adaptive control of investment projecting processes $\boldsymbol{T}_{\tau}=\left\{\tau_{k}\right\}_{k \in 0, n_{\tau}^{(\kappa p .)}}=\boldsymbol{T}_{0}=\left\{\tau_{k}\right\}_{k \in \overline{0,6}}=\left\{\tau_{0}, \tau_{1}, \ldots, \tau_{6}\right\}=$ $=\{0 ; 2 ; 4 ; 5 ; 6 ; 7 ; 8\}$, corresponding to events $\{1 ; 2 ; 5 ; 8 ; 10 ; 11 ; 13\}$ critical path $\boldsymbol{R}_{0}^{(\kappa p .)}$.

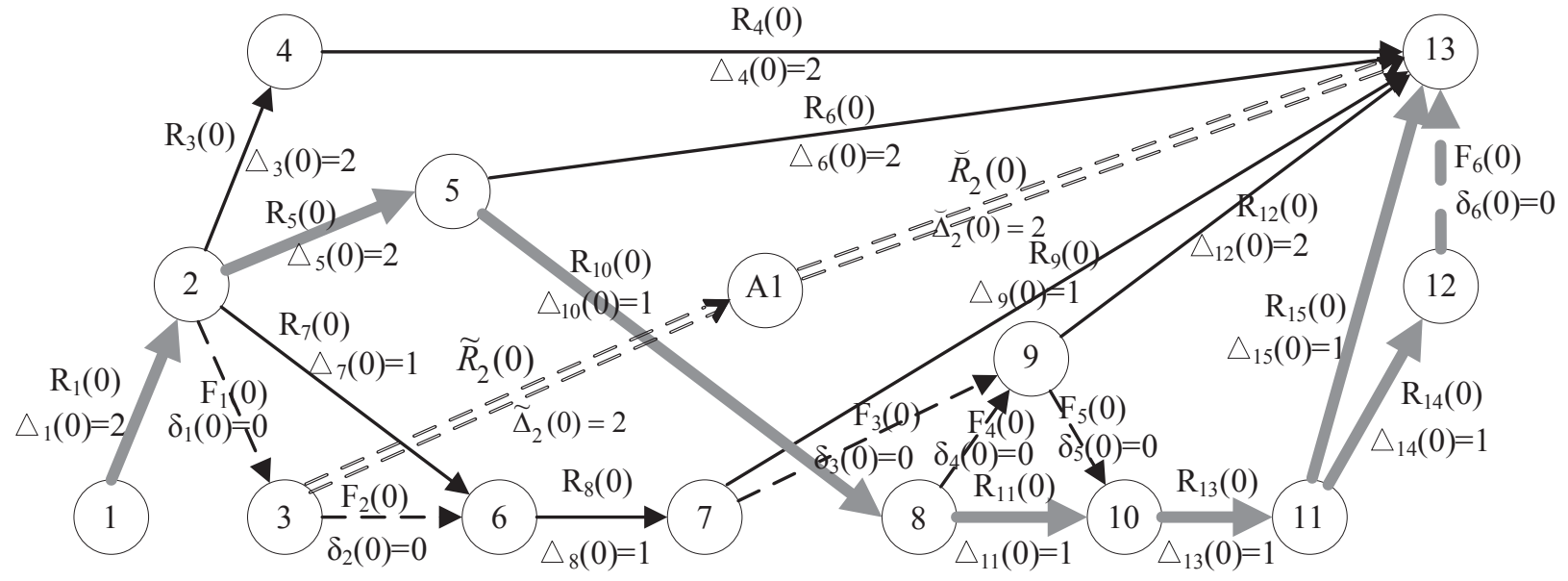

FIGURE 4. Critical paths in network implementation model of investment projecting processes $(\tau=0)$

For the formed network model, based on the found critical path and the corresponding array of the duration of the work, the task of scheduling is solved - the formation of a calendar schedule, i.e., description of the acceptable deadlines for the execution of all work operations. The schedule of all work operations for the investment project under consideration in the form of a Gantt chart is shown in Figure 5 and corresponds to 8 weeks of the investment project.

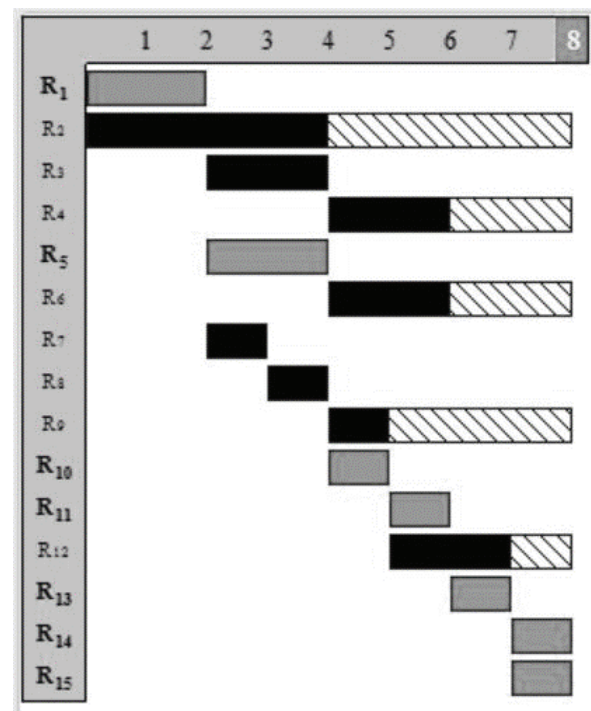

FIGURE 5. Schedule of implementation of investment projecting processes $(\tau=0)$

The abscissa indicates the duration of the project work-execution in weeks; along the ordinate axis - ordered work-operations; rectangles with black color indicate non-critical work-operations of the project; gray rectangles denote critical operations; rectangles with a dash denote free time reserves for performing work-operations.

At the third stage, the proposed intelligent computer program system for the formed network model of the investment project under consideration implements the optimization of adaptive control of investment projecting processes, which is carried out on the basis of the new method of network formalization and of adaptive project control optimization described in [1]. 
Note that in the process of implementing an investment project, all non-critical work-operations are performed at the earliest possible date prescribed by the current schedule. This assumption does not limit the method used, but is made only to reduce the description of the optimization procedure for adaptive control of investment projecting processes.

Given that in the initial period of time, i.e., $\tau=\tau_{0}=0$, there is no delay in the execution of the work-operations of the investment project under consideration, for which the latest deadline is the beginning of the time period $\tau_{1}=2$, then applying to the investment planning process under consideration the new method of network formalization and of adaptive project control optimization [1] is formed that meets the current situation $\tau_{1}$-position $\left(\tau_{1}=2\right)$ of the project $p\left(\tau_{1}\right)=\left\{\tau_{1}, \overline{\boldsymbol{R}}\left(\tau_{1} \mid \boldsymbol{R}_{0}, \boldsymbol{T}_{\tau}\right)\right\} \in \boldsymbol{P}\left(\tau_{1}\right)$, where the set of work-operations $\overline{\boldsymbol{R}}\left(\tau_{1} \mid \boldsymbol{R}_{0}, \boldsymbol{T}_{\tau}\right)=$ $=\left\{\bar{R}_{1}\left(\tau_{1}\right), \bar{R}_{2}\left(\tau_{1}\right), \ldots, \bar{R}_{m_{\tau_{1}}}\left(\tau_{1}\right)\right\}=\left\{\bar{R}_{1}\left(\tau_{1}\right), \bar{R}_{2}\left(\tau_{1}\right)\right\}$ is a set consisting of 2 elements, i.e., $m_{\tau_{1}}=2<n_{0}=15$. Moreover, $\quad p\left(\tau_{1}\right)=\left\{\tau_{1},\left\{\bar{R}_{1}\left(\tau_{1}\right), \bar{R}_{2}\left(\tau_{1}\right)\right\}\right\} \neq p^{(e)}\left(\tau_{1}\right)=\left\{\tau_{1},\left\{R_{1}^{(e)}\left(\tau_{1}\right), R_{2}^{(e)}\left(\tau_{1}\right)\right\}=\left\{\tau_{1}, \overline{\boldsymbol{R}}^{(e)}\left(\tau_{1} \mid \boldsymbol{R}_{0}, \boldsymbol{T}_{\tau}\right)\right\} \in\right.$ $\in \boldsymbol{P}\left(\tau_{1}\right)$, i.e., $p\left(\tau_{1}\right) \in\left\{\boldsymbol{P}\left(\tau_{1}\right) \backslash\left\{p^{(e)}\left(\tau_{1}\right)\right\}\right\}$ and, therefore, is not an optimal $\tau_{1}$-position, since in the set of workoperations $\left\{\bar{R}_{1}\left(\tau_{1}\right), \bar{R}_{2}\left(\tau_{1}\right)\right\}=\left\{R_{1}(0), R_{2}(0)\right\}$, by the beginning of the execution of the time period $\tau_{1}=2$, the work $\bar{R}_{2}\left(\tau_{1}\right)=R_{2}(0)$ was only partially completed (provided that it was completed at the earliest possible date), namely, only its part $\widetilde{R}_{2}\left(\tau_{1}\right)=\widetilde{R}_{2}(0) \quad$ was completed, where $\quad \bar{R}_{2}\left(\tau_{1}\right)=\widetilde{R}_{2}\left(\tau_{1}\right) \cup \breve{R}_{2}\left(\tau_{1}\right)=$ $=\widetilde{R}_{2}(0) \cup \breve{R}_{2}(0)=R_{2}(0)$, and $\breve{R}_{2}(0)-$ the part of this work remaining to be performed. Let us denote: $\widetilde{\Delta}_{2}\left(\tau_{1}\right)=\widetilde{\Delta}_{2}(0)=2$ the time in weeks spent on the work $\widetilde{R}_{2}\left(\tau_{1}\right)=\widetilde{R}_{2}(0)$, and $\breve{\Delta}_{2}\left(\tau_{1}\right)=\breve{\Delta}_{2}(0)=2-$ the time in weeks needed to complete the work $\breve{R}_{2}\left(\tau_{1}\right)=\breve{R}_{2}(0)$. In Figure 4, between events numbered 1 and 13, event A1 is marked corresponding to the beginning of a time period $\tau_{1}=2$. Then the work $\widetilde{R}_{2}\left(\tau_{1}\right)=\widetilde{R}_{2}(0)$ leaves the event at number 1 and enters the event $\mathrm{A} 1$, and the work $\breve{R}_{2}\left(\tau_{1}\right)=\breve{R}_{2}(0)$ leaves the event A1 and enters the event at number 13 (both of these works are depicted by directional dashed segments-edges). Define a set $\breve{\boldsymbol{R}}\left(\tau_{1}\right)=$ $=\left\{\breve{R}_{1}\left(\tau_{1}\right), \breve{R}_{2}\left(\tau_{1}\right), \ldots, \breve{R}_{\tau_{\tau_{1}}}\left(\tau_{1}\right)\right\}=\left\{\breve{R}_{1}\left(\tau_{1}\right)\right\}=\left\{\breve{R}_{2}(0)\right\}$ that contains the incomplete part of the work-operation $\bar{R}_{2}\left(\tau_{1}\right)=R_{2}(0)$, where $l_{\tau_{1}}=1$.

In accordance with the strategy for optimal adaptive project control $U_{a}^{(e)} \in \boldsymbol{U}_{a}$ defined in the method used [1], used for the investment projecting processes under consideration, and implemented by the $\tau_{1}$-position $p\left(\tau_{1}\right)=$ $=\left\{\tau_{1},\left\{\bar{R}_{1}\left(\tau_{1}\right), \bar{R}_{2}\left(\tau_{1}\right)\right\}\right\}=\left\{\tau_{1},\left\{R_{1}(0), R_{2}(0)\right\}\right\} \in\left\{\boldsymbol{P}\left(\tau_{1}\right) \backslash\left\{p^{(e)}\left(\tau_{1}\right)\right\}\right\}$, have:

$$
\begin{gathered}
U_{a}^{(e)}\left(p^{(e)}\left(\tau_{1}\right)\right)=\boldsymbol{R}\left(\tau_{1}\right)=\breve{\boldsymbol{R}}\left(\tau_{1}\right) \bigcup\left\{\boldsymbol{R}_{0} \backslash \overline{\boldsymbol{R}}\left(\tau_{1} \mid \boldsymbol{R}_{0}, \boldsymbol{T}_{\tau}\right)\right\}=\hat{\boldsymbol{R}}\left(\tau_{1} \mid \boldsymbol{R}_{0}, \boldsymbol{T}_{\tau}\right)= \\
=\left\{\breve{R}_{2}(0)\right\} \bigcup\left\{R_{1}(0), R_{2}(0), \ldots, R_{15}(0)\right\} \backslash\left\{\bar{R}_{1}\left(\tau_{1}\right), \bar{R}_{2}\left(\tau_{1}\right), \ldots, \bar{R}_{m_{\tau_{1}}}\left(\tau_{1}\right)\right\}=\left\{\hat{R}_{1}\left(\tau_{1}\right), \hat{R}_{2}\left(\tau_{1}\right), \ldots, \hat{R}_{n_{\tau_{1}}}\left(\tau_{1}\right)\right\}= \\
=\left\{R_{1}\left(\tau_{1}\right), R_{2}\left(\tau_{1}\right), \ldots, R_{n_{\tau_{1}}}\left(\tau_{1}\right)\right\}=\left\{\breve{R}_{2}(0), R_{3}(0), R_{4}(0), \ldots, R_{15}(0)\right\}=\boldsymbol{R}_{\tau_{1}},
\end{gathered}
$$

where $n_{\tau_{1}}=n_{0}-m_{\tau_{1}}+l_{\tau_{1}}=15-2+1=14$. Then, given that $\boldsymbol{R}_{\tau_{1}} \neq \varnothing$, it relies: $s:=s+1 ; t_{s}:=\tau_{1} ; p_{a}^{(e)}\left(t_{s}\right):=$ $:=p\left(\tau_{1}\right) ; \quad$ based $\quad$ on the data contained in the array $\Delta(\tau)=\left\{\Delta_{1}(\tau), \Delta_{2}(\tau), \ldots, \Delta_{15}(\tau)\right\}=$ $=\left\{\Delta_{1}(0), \Delta_{2}(0), \ldots, \Delta_{15}(0)\right\}=\Delta_{\tau}$, as well as the value $\widetilde{\Delta}_{2}\left(\tau_{1}\right)=\widetilde{\Delta}_{2}(0)=2$, a new array of the duration of the 
work-operations

$$
\Delta\left(\tau_{1}\right)=\left\{\Delta_{1}\left(\tau_{1}\right), \Delta_{2}\left(\tau_{1}\right), \ldots, \Delta_{14}\left(\tau_{1}\right)\right\}=\left\{\breve{\Delta}_{2}(0), \Delta_{3}(0), \Delta_{4}(0), \ldots, \Delta_{15}(0)\right\}=\Delta_{\tau_{1}}
$$

execution corresponding to the new period of time $\tau=\tau_{1}$ corresponding to the array of work-operations $\boldsymbol{R}_{\tau_{1}}$ is calculated; relies $\tau:=\tau_{1}=2$.

Further, on the basis of the method used [1], a new scheduling task is solved that corresponds to a time period $\tau=2$ and an established set of work-operations $\boldsymbol{R}^{(e)}(\tau)=\left\{R_{1}(\tau), R_{2}(\tau), \ldots, R_{14}(\tau)\right\}=\left\{\breve{R}_{2}(0), R_{3}(0), \ldots\right.$, $\left.R_{15}(0)\right\}=\boldsymbol{R}_{\tau_{1}}$, i.e., the only new critical path of the investment project under consideration $\boldsymbol{R}^{(\kappa p .)}(\tau)=$ $=\left\{R_{1}^{(\kappa p .)}\left(\tau ; \tau_{1}\right), R_{2}^{(\kappa p .)}\left(\tau_{1} ; \tau_{2}\right), \ldots, R_{n_{\tau}^{(\kappa p .)}}^{(\kappa p .)}\left(\tau_{n_{\tau}^{(\kappa p .)}-1} ; \tau_{n_{\tau}^{(\kappa p .)}}\right)\right\}=\left\{R_{1}^{(\kappa p .)}(2 ; 4), R_{2}^{(\kappa p .)}(4 ; 5), R_{3}^{(\kappa p .)}(5 ; 6), \quad R_{4}^{(\kappa p .)}(6 ; 7)\right.$, $\left.R_{5}^{(\kappa p .)}(7 ; 8)\right\}=\boldsymbol{R}_{\tau}^{(\kappa p .)}$ is being formed, which is part of the previous critical path (Figure 4) and consists of a set of work-operations $\left\{R_{9}(\tau), R_{10}(\tau), R_{12}(\tau), R_{14}(\tau)\right\}=\left\{R_{10}(0), R_{11}(0), R_{13}(0), R_{15}(0)\right\}$, as well as a new calendar schedule, which is part of the previous schedule (Figure 5). These elements of solving the problem under consideration correspond to a new array of time periods for implementing the optimization of adaptive control of investment projecting processes $\boldsymbol{T}_{\tau}=\left\{\tau_{k}\right\}_{k \in 1, n_{\tau}^{(\kappa p .)}}=\left\{\tau_{k}\right\}_{k \in \overline{0,5}}=\{2,4,5,6,7,8\}=\left\{\tau_{0}, \tau_{1}, \ldots, \tau_{5}\right\}, \quad$ where $\tau_{0}=\tau=2$, and together with critical time $T_{\tau}^{(e)}=8$ they are remembered.

During the period of time $\tau=2$, there is also no delay in the execution of work-operations, for which the latest date for their execution is the beginning of the period of time $\tau_{1}=4$, then applying the new method of network formalization and of adaptive project control optimization [1] to the processes of investment projecting considered, it is formed that meets the prevailing situations $\tau_{1}$-position $\left(\tau_{1}=4\right)$ of the implementation of investment projecting processes $p\left(\tau_{1}\right)=\left\{\tau_{1}, \overline{\boldsymbol{R}}\left(\tau_{1} \mid \boldsymbol{R}_{0}, \boldsymbol{T}_{\tau}\right)\right\} \in \boldsymbol{P}\left(\tau_{1}\right)$, where $\boldsymbol{P}\left(\tau_{1}\right)$ is the set of all admissible $\tau_{1}$-positions, and the set of work-operations $\quad \overline{\boldsymbol{R}}\left(\tau_{1} \mid \boldsymbol{R}_{0}, \boldsymbol{T}_{\tau}\right)=\left\{\bar{R}_{1}\left(\tau_{1}\right), \bar{R}_{2}\left(\tau_{1}\right), \ldots, \bar{R}_{m_{\tau_{1}}}\left(\tau_{1}\right)\right\}=\left\{\bar{R}_{1}\left(\tau_{1}\right), \bar{R}_{2}\left(\tau_{1}\right), \ldots, \bar{R}_{6}\left(\tau_{1}\right)\right\}=\left\{R_{1}(0), R_{2}(0)\right.$, $\left.R_{3}(0), R_{5}(0), R_{7}(0), R_{8}(0)\right\}$ is a set consisting of 6 elements, i.e., $m_{\tau_{1}}=6<n_{0}=15$. Moreover $p\left(\tau_{1}\right)=\left\{\tau_{1}\right.$, $\left.\left\{\bar{R}_{1}\left(\tau_{1}\right), \bar{R}_{2}\left(\tau_{1}\right), \ldots, \bar{R}_{6}\left(\tau_{1}\right)\right\}\right\}=p^{(e)}\left(\tau_{1}\right)=\left\{\tau_{1},\left\{R_{1}^{(e)}\left(\tau_{1}\right), R_{2}^{(e)}\left(\tau_{1}\right), \ldots, R_{6}^{(e)}\left(\tau_{1}\right)\right\}\right\}=\left\{\tau_{1}, \overline{\boldsymbol{R}}^{(e)}\left(\tau_{1} \mid \boldsymbol{R}_{0}, \boldsymbol{T}_{\tau}\right)\right\} \in \boldsymbol{P}\left(\tau_{1}\right)$ where $\overline{\boldsymbol{R}}^{(e)}\left(\tau_{1} \mid \boldsymbol{R}_{0}, \boldsymbol{T}_{\tau}\right)=\left\{R_{1}^{(e)}\left(\tau_{1}\right), R_{2}^{(e)}\left(\tau_{1}\right), \ldots, R_{6}^{(e)}\left(\tau_{1}\right)\right\}$ and, therefore, is optimal, because the set of workoperations $\left\{\bar{R}_{1}\left(\tau_{1}\right), \bar{R}_{2}\left(\tau_{1}\right), \ldots, \bar{R}_{6}\left(\tau_{1}\right)\right\}=\left\{R_{1}(0), R_{2}(0), R_{3}(0), R_{5}(0), R_{7}(0), R_{8}(0)\right\}$ is such, and only such a set of work, which should be completed by the time period $\tau_{1}=4$, provided that they are implemented at the earliest possible dates determined for them by the new calendar.

In accordance with the strategy for optimal adaptive project control $U_{a}^{(e)} \in \boldsymbol{U}_{a}$ for the considered processes of investment projecting defined in the method used [1], and the realized $\tau_{1}$-position $p^{(e)}\left(\tau_{1}\right)=\left\{\tau_{1}\right.$, $\left.\left\{R_{1}^{(e)}\left(\tau_{1}\right), R_{2}^{(e)}\left(\tau_{1}\right), \ldots, R_{6}^{(e)}\left(\tau_{1}\right)\right\}\right\} \in \boldsymbol{P}\left(\tau_{1}\right)$, have:

$$
\begin{gathered}
U_{a}^{(e)}\left(p^{(e)}\left(\tau_{1}\right)\right)=\boldsymbol{R}^{(e)}\left(\tau_{1}\right)=\left\{\boldsymbol{R}_{0} \backslash \overline{\boldsymbol{R}}^{(e)}\left(\tau_{1} \mid \boldsymbol{R}_{0}, \boldsymbol{T}_{\tau}\right)\right\}=\hat{\boldsymbol{R}}^{(e)}\left(\tau_{1} \mid \boldsymbol{R}_{0}, \boldsymbol{T}_{\tau}\right)= \\
=\left\{R_{1}(0), R_{2}(0), \ldots, R_{15}(0)\right\} \backslash\left\{\bar{R}_{1}\left(\tau_{1}\right), \bar{R}_{2}\left(\tau_{1}\right), \ldots, \bar{R}_{m_{\tau_{1}}}\left(\tau_{1}\right)\right\}=\left\{\hat{R}_{1}^{(e)}\left(\tau_{1}\right), \hat{R}_{2}^{(e)}\left(\tau_{1}\right), \ldots, \hat{R}_{n_{\tau_{1}}}^{(e)}\left(\tau_{1}\right)\right\}= \\
=\left\{R_{1}\left(\tau_{1}\right), R_{2}\left(\tau_{1}\right), \ldots, R_{n_{\tau_{1}}}\left(\tau_{1}\right)\right\}=\left\{R_{4}(0), R_{6}(0), R_{9}(0), R_{10}(0), \ldots, R_{15}(0)\right\}=\boldsymbol{R}_{\tau_{1}},
\end{gathered}
$$


where $n_{\tau_{1}}=n_{0}-m_{\tau_{1}}=15-6=9$. Then, given that $\boldsymbol{R}\left(\tau_{1}\right)=\left\{R_{1}\left(\tau_{1}\right), R_{2}\left(\tau_{1}\right), \ldots, R_{9}\left(\tau_{1}\right)\right\}=\boldsymbol{R}_{\tau_{1}} \neq \varnothing$, it relies: $s:=s+1 ; t_{s}:=\tau_{1} ; p_{a}^{(e)}\left(t_{s}\right):=p^{(e)}\left(\tau_{1}\right) ;$ on the basis of the data contained in the array $\Delta(\tau)=\left\{\Delta_{1}(\tau), \Delta_{2}(\tau), \ldots\right.$, $\left.\Delta_{14}(\tau)\right\}=\left\{\breve{\Delta}_{2}(0), \Delta_{3}(0), \Delta_{4}(0), \ldots, \Delta_{15}(0)\right\}=\Delta_{\tau}$, a new array of the duration of the execution of work-operations $\Delta\left(\tau_{1}\right)=\left\{\Delta_{1}\left(\tau_{1}\right), \Delta_{2}\left(\tau_{1}\right), \ldots, \Delta_{9}\left(\tau_{1}\right)\right\}=\left\{\Delta_{4}(0), \Delta_{6}(0), \Delta_{9}(0), \Delta_{10}(0), \ldots, \Delta_{15}(0)\right\}=\Delta_{\tau_{1}}$ corresponding to the new time period $\tau=\tau_{1}$ is calculated corresponding to the array of work-operations $\boldsymbol{R}_{\tau_{1}}$; relies $\tau:=\tau_{1}=4$.

Further, on the basis of the method used [1], a new scheduling task is solved that corresponds to a time period $\tau=4$ and an established set of work-operations $\boldsymbol{R}^{(e)}(\tau)=\left\{R_{1}(\tau), R_{2}(\tau), \ldots, R_{9}(\tau)\right\}=$ $=\left\{R_{4}(0), R_{6}(0), R_{9}(0), R_{10}(0), \ldots, R_{15}(0)\right\}=\boldsymbol{R}_{\tau_{1}}$, i.e., the only new critical path of the investment project under consideration $\boldsymbol{R}^{(\kappa p .)}(\tau)=\left\{R_{1}^{(\kappa p .)}(4 ; 5), R_{2}^{(\kappa p .)}(5 ; 6), R_{3}^{(\kappa p .)}(6 ; 7), R_{4}^{(\kappa p .)}(7 ; 8)\right\}=\boldsymbol{R}_{\tau}^{(\kappa p .)}$ is being formed, which is part of the previous critical path (Figure 4) and consists of a set of work-operations $\left\{R_{4}(\tau), R_{5}(\tau), R_{7}(\tau), R_{9}(\tau)\right\}=$ $=\left\{R_{10}(0), R_{11}(0), R_{13}(0), R_{15}(0)\right\}$, as well as a new calendar schedule, which is part of the previous schedule (Figure 5). These elements of solving the problem under consideration correspond to a new array of time periods for implementing the optimization of adaptive control of investment projecting processes $\boldsymbol{T}_{\tau}=\left\{\tau_{k}\right\}_{k \in 1, n_{\tau}^{(k p .)}}=\left\{\tau_{k}\right\}_{k \in \overline{0,4}}=\{4,5,6,7,8\}=\left\{\tau_{0}, \tau_{1}, \tau_{2}, \tau_{3}, \tau_{4}\right\}$, where $\tau_{0}=\tau=4$ and along with critical time $T_{\tau}^{(e)}=8$ they are remembered.

Let us consider in more detail the work-operation $R_{2}(\tau)=R_{6}(0)$ - "Installation and installation of equipment". The investment project provides for the introduction of a new production line for the production of glazed confectionery. When assembling the production line, a technical problem arose - the OK400 cooling tunnel, which has two sections and is necessary for cooling confectionery products, cannot be put into operation (see Figure 2). To generate the cold, powerful French-made compressors were installed on it, and when checking it was found that there were no tubes for draining the condensate out. Due to the incomplete equipment and the need for additional work, it took 5 weeks to complete the work-operation $R_{2}(\tau)=R_{6}(0)$, and not 2 weeks as originally planned, i.e., her duration her performance increased by 3 weeks.

Thus, there was a delay of 3 weeks during the execution of work $R_{2}(\tau)=R_{6}(0)$, at the same time, by the beginning of the time period $\tau_{1}=5$, i.e., in a period of time $\tau=4$, only a part of it $\widetilde{R}_{2}(\tau)=\widetilde{R}_{6}(0)$ is completed, and the rest of it $\breve{R}_{2}(\tau)=\breve{R}_{6}(0)$ should begin to be performed in a period of time $\tau_{1}=5$, while have $R_{2}(\tau)=\widetilde{R}_{2}(\tau) \cup \widetilde{R}_{2}(\tau)=\widetilde{R}_{6}(0) \cup \widetilde{R}_{6}(0)=R_{6}(0)$. Let us denote $\widetilde{\Delta}_{2}(\tau)=\widetilde{\Delta}_{6}(0)=1-$ the duration of the work $\widetilde{R}_{2}(\tau)=\widetilde{R}_{6}(0)$ and $\breve{\Delta}_{2}(\tau)=\breve{\Delta}_{6}(0)=4 \quad-$ the duration of the work $\breve{R}_{2}(\tau)=\breve{R}_{6}(0)$, then we have: $\Delta_{2}(\tau)=\Delta_{6}(0)+3=2+3=5$. Between events with numbers 5 and 13 , we introduce event A5, which corresponds to the completion of work $\widetilde{R}_{2}(\tau)=\widetilde{R}_{6}(0)$ and the beginning of work $\breve{R}_{2}(\tau)=\breve{R}_{6}(0)$, i.e., completion of the control period $\tau=4$ and the beginning of the control period $\tau_{1}=\tau+1=4+1=5$ (Figure 6). For the current new situation, it is necessary to change the array of work-operations $\boldsymbol{R}^{(e)}(\tau)=\left\{R_{1}(\tau), R_{2}(\tau), \ldots\right.$, $\left.R_{9}(\tau)\right\}==\left\{R_{4}(0), R_{6}(0), R_{9}(0), R_{10}(0), \ldots, R_{15}(0)\right\}=\boldsymbol{R}_{\tau}$, namely, taking into account the increase in the duration of the work-operation $R_{2}(\tau)=R_{6}(0)$, it is already described by the array $\boldsymbol{R}^{(e)}(\tau)=\left\{R_{1}(\tau), R_{2}(\tau), \ldots, R_{10}(\tau)\right\}=$ $=\left\{R_{4}(0), \widetilde{R}_{6}(0), \breve{R}_{6}(0), R_{9}(0), R_{10}(0), \ldots, R_{15}(0)\right\}=\boldsymbol{R}_{\tau}$. 
In the period of time $\tau_{1}=5$, taking into account the increase in the duration of the period of the work-operation $R_{2}(\tau)=R_{6}(0)$, in accordance with the method used [1], a situation corresponding to the current situation is formed $\tau_{1}$ position $\left(\tau_{1}=5\right.$ ) of the implementation of investment projecting processes $p\left(\tau_{1}\right)=\left\{\tau_{1}, \overline{\boldsymbol{R}}\left(\tau_{1} \mid \boldsymbol{R}_{0}, \boldsymbol{T}_{\tau}\right)\right\} \in \boldsymbol{P}\left(\tau_{1}\right)$, where the set of work-operations $\overline{\boldsymbol{R}}\left(\tau_{1} \mid \boldsymbol{R}_{0}, \boldsymbol{T}_{\tau}\right)=\left\{\bar{R}_{1}\left(\tau_{1}\right), \bar{R}_{2}\left(\tau_{1}\right), \ldots, \bar{R}_{m_{\tau_{1}}}\left(\tau_{1}\right)\right\}=\left\{\bar{R}_{1}\left(\tau_{1}\right), \bar{R}_{2}\left(\tau_{1}\right), \ldots, \bar{R}_{10}\left(\tau_{1}\right)\right\}$ is a set of 10 elements, those $m_{\tau_{1}}=10<n_{0}=15$. Moreover, $p\left(\tau_{1}\right)=\left\{\tau_{1},\left\{\bar{R}_{1}\left(\tau_{1}\right), \bar{R}_{2}\left(\tau_{1}\right), \ldots, \bar{R}_{10}\left(\tau_{1}\right)\right\}\right\} \neq$ $\neq p^{(e)}\left(\tau_{1}\right)=\left\{\tau_{1},\left\{R_{1}^{(e)}\left(\tau_{1}\right), R_{2}^{(e)}\left(\tau_{1}\right), \ldots, R_{10}^{(e)}\left(\tau_{1}\right)\right\}\right\}=\left\{\tau_{1}, \overline{\boldsymbol{R}}^{(e)}\left(\tau_{1} \mid \boldsymbol{R}_{0}, \boldsymbol{T}_{\tau}\right)\right\} \in \boldsymbol{P}\left(\tau_{1}\right), \quad$ i.e., $\quad p\left(\tau_{1}\right) \in\left\{\boldsymbol{P}\left(\tau_{1}\right) \backslash\right.$ $\left.\backslash\left\{p^{(e)}\left(\tau_{1}\right)\right\}\right\}$ and, therefore, is not an optimal $\tau_{1}$-position, since in the set of work-operations $\left\{\bar{R}_{1}\left(\tau_{1}\right), \bar{R}_{2}\left(\tau_{1}\right), \ldots, \bar{R}_{10}\left(\tau_{1}\right)\right\}=\left\{R_{1}(0), R_{2}(0), \ldots, R_{10}(0)\right\}$ to the beginning of the execution of the period of time $\tau_{1}=5$ the work $\bar{R}_{4}\left(\tau_{1}\right)=R_{4}(0)$ and $\bar{R}_{6}\left(\tau_{1}\right)=R_{6}(0)$ is only partially performed (provided that they are completed at the earliest possible date), namely, only part $\widetilde{R}_{4}\left(\tau_{1}\right)=\widetilde{R}_{4}(0)$ of the work $\bar{R}_{4}\left(\tau_{1}\right)$ is done, where $\bar{R}_{4}\left(\tau_{1}\right)=\widetilde{R}_{4}\left(\tau_{1}\right) \cup \breve{R}_{4}\left(\tau_{1}\right)=\widetilde{R}_{4}(0) \cup \breve{R}_{4}(0)=R_{4}(0)$, and $\breve{R}_{4}\left(\tau_{1}\right)=\breve{R}_{4}(0)$ - the remaining part of this work, similarly, only part $\widetilde{R}_{6}\left(\tau_{1}\right)=\widetilde{R}_{6}(0)$ work $\bar{R}_{6}\left(\tau_{1}\right)$, where $\bar{R}_{6}\left(\tau_{1}\right)=\widetilde{R}_{6}\left(\tau_{1}\right) \cup \breve{R}_{6}\left(\tau_{1}\right)=\widetilde{R}_{6}(0) \cup \breve{R}_{6}(0)=R_{6}(0)$, a $\breve{R}_{6}\left(\tau_{1}\right)=\breve{R}_{6}(0)$ is the remaining part of this work. Let us denote $\widetilde{\Delta}_{4}\left(\tau_{1}\right)=\widetilde{\Delta}_{4}(0)=1$ the time in weeks spent on the work $\widetilde{R}_{4}\left(\tau_{1}\right)=\widetilde{R}_{4}(0)$, and after $\breve{\Delta}_{4}\left(\tau_{1}\right)=\breve{\Delta}_{4}(0)=1-$ the time in weeks needed to complete the work $\breve{R}_{4}\left(\tau_{1}\right)=\breve{R}_{4}(0)$. Similarly, we denote $\widetilde{\Delta}_{6}\left(\tau_{1}\right)=\widetilde{\Delta}_{6}(0)=1$ the time in weeks spent on the work $\widetilde{R}_{6}\left(\tau_{1}\right)=\widetilde{R}_{6}(0)$, and after $\breve{\Delta}_{6}\left(\tau_{1}\right)=\breve{\Delta}_{6}(0)=4-$ the time in weeks needed to complete the work $\breve{R}_{6}\left(\tau_{1}\right)=\breve{R}_{6}(0)$. Define a set $\breve{\boldsymbol{R}}\left(\tau_{1}\right)=\left\{\breve{R}_{1}\left(\tau_{1}\right), \breve{R}_{2}\left(\tau_{1}\right), \ldots, \breve{R}_{\tau_{\tau_{1}}}\left(\tau_{1}\right)\right\}=\left\{\breve{R}_{1}\left(\tau_{1}\right), \breve{R}_{2}\left(\tau_{1}\right)\right\}=\left\{\breve{R}_{4}(0), \breve{R}_{6}(0)\right\}$ that contains the incomplete parts of the work-operations $\bar{R}_{4}\left(\tau_{1}\right)=R_{4}(0)$ and $\bar{R}_{6}\left(\tau_{1}\right)=R_{6}(0)$, where $l_{\tau_{1}}=2$.

In Figure 6 between events numbered 4 and 13, event A4 was introduced, which corresponds to the completion of work $\widetilde{R}_{4}(0)$ and the beginning of work $\breve{R}_{4}(0)$, i.e., the end of the control period $\tau=4$ and the beginning of the control period $\tau_{1}=5$.

In accordance with the strategy for optimal adaptive project control $U_{a}^{(e)} \in \boldsymbol{U}_{a}$ for the considered processes of investment projecting defined in the method used [1], and the realized $\tau_{1}$-position $p\left(\tau_{1}\right)=$

$$
\begin{gathered}
=\left\{\tau_{1},\left\{\bar{R}_{1}\left(\tau_{1}\right), \bar{R}_{2}\left(\tau_{1}\right), \ldots, \bar{R}_{10}\left(\tau_{1}\right)\right\}\right\}=\left\{\tau_{1},\left\{R_{1}(0), R_{2}(0), \ldots, R_{10}(0)\right\}\right\} \in\left\{\boldsymbol{P}\left(\tau_{1}\right) \backslash\left\{p\left(p^{(e)}\left(\tau_{1}\right)\right\}\right\},\right. \text { have: } \\
\qquad U_{a}^{(e)}\left(p^{(e)}\left(\tau_{1}\right)\right)=\boldsymbol{R}\left(\tau_{1}\right)=\breve{\boldsymbol{R}}\left(\tau_{1}\right) \bigcup\left\{\boldsymbol{R}_{0} \backslash \overline{\boldsymbol{R}}\left(\tau_{1} \mid \boldsymbol{R}_{0}, \boldsymbol{T}_{\tau}\right)\right\}=\hat{\boldsymbol{R}}\left(\tau_{1} \mid \boldsymbol{R}_{0}, \boldsymbol{T}_{\tau}\right)= \\
=\left\{\breve{R}_{4}(0), \breve{R}_{6}(0)\right\} \bigcup\left\{R_{1}(0), R_{2}(0), \ldots, R_{15}(0)\right\} \backslash\left\{\bar{R}_{1}\left(\tau_{1}\right), \bar{R}_{2}\left(\tau_{1}\right), \ldots, \bar{R}_{m_{\tau_{1}}}\left(\tau_{1}\right)\right\}=\left\{\hat{R}_{1}\left(\tau_{1}\right), \hat{R}_{2}\left(\tau_{1}\right), \ldots, \hat{R}_{n_{\tau_{1}}}\left(\tau_{1}\right)\right\}= \\
=\left\{R_{1}\left(\tau_{1}\right), R_{2}\left(\tau_{1}\right), \ldots, R_{n_{\tau_{1}}}\left(\tau_{1}\right)\right\}=\left\{\breve{R}_{4}(0), \breve{R}_{6}(0), R_{11}(0), R_{12}(0), \ldots, R_{15}(0)\right\}=\boldsymbol{R}_{\tau_{1}},
\end{gathered}
$$

where $n_{\tau_{1}}=n_{0}-m_{\tau_{1}}+l_{\tau_{1}}=15-10+2=7$; Then, given that $\boldsymbol{R}_{\tau_{1}} \neq \varnothing$, it relies: $s:=s+1 ; t_{s}:=\tau_{1} ; p_{a}^{(e)}\left(t_{s}\right):=$ $:=p\left(\tau_{1}\right) ; \quad$ based $\quad$ on the data contained in the array $\Delta(\tau)=\left\{\Delta_{1}(\tau), \Delta_{2}(\tau), \ldots, \Delta_{9}(\tau)\right\}=$ 
$=\left\{\Delta_{4}(0), \Delta_{6}(0), \Delta_{9}(0), \Delta_{10}(0), \ldots, \Delta_{15}(0)\right\}=\Delta_{\tau}, \quad$ as $\quad$ well $\quad$ as $\quad$ the values $\quad \widetilde{\Delta}_{4}\left(\tau_{1}\right)=\widetilde{\Delta}_{4}(0)=1 \quad$ and $\widetilde{\Delta}_{6}\left(\tau_{1}\right)=\widetilde{\Delta}_{6}(0)=1$, a new array of the duration of the work-operations $\Delta\left(\tau_{1}\right)=\left\{\Delta_{1}\left(\tau_{1}\right), \Delta_{2}\left(\tau_{1}\right), \ldots, \Delta_{7}\left(\tau_{1}\right)\right\}=$ $=\left\{\breve{\Delta}_{4}(0), \breve{\Delta}_{6}(0), \Delta_{11}(0), \Delta_{12}(0), \ldots, \Delta_{15}(0)\right\}=\Delta_{\tau_{1}}$ corresponding to the new period of time $\tau=\tau_{1}$ corresponding to the array of work-operations $\boldsymbol{R}_{\tau_{1}}$ is calculated; relies $\tau:=\tau_{1}=5$.

Further, on the basis of the method used [1], a new scheduling task is solved corresponding to the time period $\tau=5$ and the formed set of work-operations $\boldsymbol{R}^{(e)}(\tau)=\left\{R_{1}(\tau), R_{2}(\tau), \ldots, R_{7}(\tau)\right\}=\left\{\breve{R}_{4}(0), \breve{R}_{6}(0), R_{11}(0)\right.$, $\left.R_{12}(0), \ldots, R_{15}(0)\right\}=\boldsymbol{R}_{\tau_{1}}$, that is, the only new critical path of the investment planning process $\boldsymbol{R}^{(\kappa p .)}(\tau)=$ $=\left\{R_{1}^{(\kappa p .)}(5 ; 9)\right\}=\boldsymbol{R}_{\tau}^{(\kappa p .)}$ is being formed, which consists of one work $R_{2}(\tau)=\breve{R}_{6}(0)$ (Figure 6), as well as a new calendar schedule (Figure 7), an increase in the duration of the work is marked in light gray). These elements of solving the problem under consideration correspond to a new array of time periods for implementing optimization of adaptive control of investment projecting processes $\boldsymbol{T}_{\tau}=\left\{\tau_{k}\right\}_{k \in 1, n_{\tau}^{(k p .)}}=\left\{\tau_{k}\right\}_{k \in \overline{0,1}}=\{5,9\}=\left\{\tau_{0}, \tau_{1}\right\}$, where $\tau_{0}=\tau=5$, and together with a new critical time $T_{\tau}^{(e)}=9$ they are remembered.

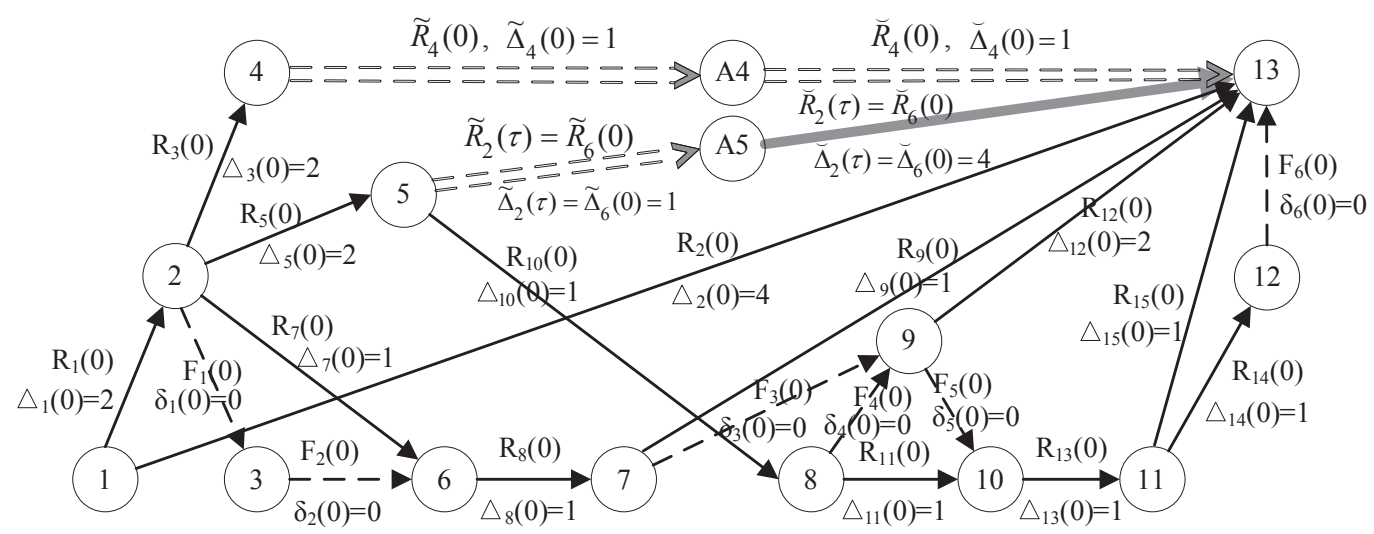

FIGURE 6. Critical path in network model for implementation of investment projecting processes $(\tau=5)$

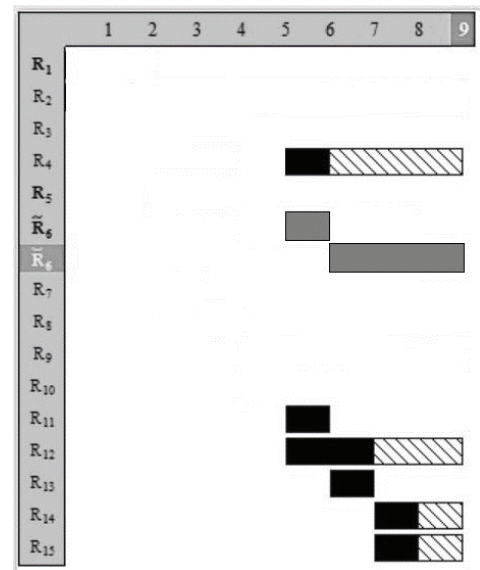

FIGURE 7. Schedule for implementation of investment projecting processes $(\tau=5$ ) 
During the period of time $\tau=5$ there is no delay in the performance of work-operations for which the most recent deadline is the critical time $T_{\tau}^{(e)}=\tau_{1}=9$. Then, after the start of the time period $\tau_{1}=9$, in whole or in part, work-operations for which the least early date for their execution is time $\tau_{1}=9$, i.e., a time period of 9 weeks, in accordance with the method used to optimize adaptive control of investment projecting processes [1] and similarly to the procedure described for a time period $\tau=4$, the following elements of the proposed solution are constructed:

1) $\tau_{1}$-position $\left(\tau_{1}=9\right)$ of the implementation of investment projecting processes $p\left(\tau_{1}\right)=$ $=\left\{\tau_{1}, \overline{\boldsymbol{R}}\left(\tau_{1} \mid \boldsymbol{R}_{0}, \boldsymbol{T}_{\tau}\right)\right\} \in \boldsymbol{P}\left(\tau_{1}\right), \quad$ where $\quad \overline{\boldsymbol{R}}\left(\tau_{1} \mid \boldsymbol{R}_{0}, \boldsymbol{T}_{\tau}\right)=\left\{\bar{R}_{1}\left(\tau_{1}\right), \bar{R}_{2}\left(\tau_{1}\right), \ldots, \bar{R}_{m_{\tau_{1}}}\left(\tau_{1}\right)\right\}=\left\{\bar{R}_{1}\left(\tau_{1}\right), \bar{R}_{2}\left(\tau_{1}\right), \ldots\right.$, $\left.\bar{R}_{15}\left(\tau_{1}\right)\right\}$ the set of work-operations is a set consisting of 15 elements, i.e., $m_{\tau_{1}}=15=n_{0}=15$. In this case $p\left(\tau_{1}\right)=\left\{\tau_{1},\left\{\bar{R}_{1}\left(\tau_{1}\right),\left\{\bar{R}_{2}\left(\tau_{1}\right), \ldots,\left\{\bar{R}_{15}\left(\tau_{1}\right)\right\}\right\}=p^{(e)}\left(\tau_{1}\right)=\left\{\tau_{1},\left\{R_{1}^{(e)}\left(\tau_{1}\right), R_{2}^{(e)}\left(\tau_{1}\right), \ldots, R_{15}^{(e)}\left(\tau_{1}\right)\right\}\right\}=\left\{\tau_{1}\right.\right.\right.$, $\left.\overline{\boldsymbol{R}}^{(e)}\left(\tau_{1} \mid \boldsymbol{R}_{0}, \boldsymbol{T}_{\tau}\right)\right\} \in \boldsymbol{P}\left(\tau_{1}\right), \quad$ where $\quad \overline{\boldsymbol{R}}^{(e)}\left(\tau_{1} \mid \boldsymbol{R}_{0}, \boldsymbol{T}_{\tau}\right)=\left\{R_{1}^{(e)}\left(\tau_{1}\right), R_{2}^{(e)}\left(\tau_{1}\right), \ldots, R_{15}^{(e)}\left(\tau_{1}\right)\right\}=\left\{R_{1}(0), R_{2}(0), \ldots\right.$, $\left.R_{15}(0)\right\}$;

2) the output array of the implementation of the strategy of optimal adaptive control of investment projecting processes $\quad U_{a}^{(e)}\left(p^{(e)}\left(\tau_{1}\right)\right)=\boldsymbol{R}^{(e)}\left(\tau_{1}\right)=\left\{\boldsymbol{R}_{0} \backslash \overline{\boldsymbol{R}}^{(e)}\left(\tau_{1} \mid \boldsymbol{R}_{0}, \boldsymbol{T}_{\tau}\right)\right\}=\hat{\boldsymbol{R}}^{(e)}\left(\tau_{1} \mid \boldsymbol{R}_{0}, \boldsymbol{T}_{\tau}\right)=\left\{\hat{R}_{1}^{(e)}\left(\tau_{1}\right), \hat{R}_{2}^{(e)}\left(\tau_{1}\right), \ldots\right.$, $\left.\hat{R}_{n_{\tau_{1}}}^{(e)}\left(\tau_{1}\right)\right\}=\left\{R_{1}\left(\tau_{1}\right), R_{2}\left(\tau_{1}\right), \ldots, R_{n_{\tau_{1}}}\left(\tau_{1}\right)\right\}=\varnothing=\boldsymbol{R}_{\tau_{1}}$, where $n_{\tau_{1}}=n_{0}-m_{\tau_{1}}=15-15=0$.

Then, on the basis of the optimal adaptive project control strategy $U_{a}^{(e)} \in \boldsymbol{U}_{a}$ defined in the method used [1], used for the investment projecting processes under consideration, and taking into account that $\overline{\boldsymbol{R}}^{(e)}\left(\tau_{1} \mid \boldsymbol{R}_{0}, \boldsymbol{T}_{\tau}\right)=$ $=\left\{R_{1}^{(e)}\left(\tau_{1}\right), R_{2}^{(e)}\left(\tau_{1}\right), \ldots, R_{15}^{(e)}\left(\tau_{1}\right)\right\}=\left\{R_{1}(0), R_{2}(0), \ldots, R_{15}(0)\right\}$, i.e., $m_{\tau_{1}}=n_{0}=15$ and $\boldsymbol{R}^{(e)}\left(\tau_{1}\right)=\boldsymbol{R}_{\tau_{1}}=\varnothing$, then it turns out that by the time period $T_{\tau}^{(e)}=\tau+4=\tau_{1}=9$ all the work-operations have been implemented that describe the processes of investment projecting under consideration. Therefore, the process of optimizing adaptive control of the considered processes of investment projecting, i.e., the formation and implementation of the strategy $U_{a}^{(e)} \in \boldsymbol{U}_{a}$, considered completed, relies on: $s:=s+1 ; t_{s}:=\tau_{1}=5 ; p_{a}^{(e)}\left(t_{s}\right):=p^{(e)}\left(\tau_{1}\right)$; and the transition to the formation of the final (output) results of solving this problem is carried out.

At the fourth stage, the output results of the process of optimizing adaptive control of the investment project under consideration are formed, i.e., a description of the elements of the formation and implementation of the strategy $U_{a}^{(e)} \in \boldsymbol{U}_{a}$ is carried out, and in accordance with paragraph 14 of the method used [1] - this is the following data: $\boldsymbol{R}_{a}^{(e)}=\boldsymbol{R}(0)=\left\{R_{1}(0), R_{2}(0), \ldots, R_{n_{0}}(0)\right\}=\boldsymbol{R}_{0}=\left\{R_{1}(0), R_{2}(0), \ldots, R_{15}(0)-\right.$ the initial set of work-operations of the investment project; $\boldsymbol{W} \boldsymbol{M}_{a}^{(e)}=\boldsymbol{W M}_{0}^{(e)}(\boldsymbol{R}(0))$ - optimal network model; $p_{a}^{(e)}\left(t_{k}\right)$ - a set of $t_{k}$-positions $k \in \overline{1, s}$ corresponding to the implementation of the strategy of optimal adaptive control of investment projecting processes $U_{a}^{(e)} ; \boldsymbol{T}_{a}^{(e)}=T_{\tau}^{(e)}=T_{5}^{(e)}=9$ - the optimal time for the implementation of the investment project, corresponding to the implementation of the strategy for optimal adaptive control of investment projecting processes $U_{a}^{(e)}$.

The results obtained are displayed in a form convenient for the business entity (the decision maker) that implements the process of optimizing the control of business planning, for example, in the form of appropriate tables, graphs or charts. 
The general scheme for implementing the optimization of adaptive control of investment projecting processes is shown in Figure 8.

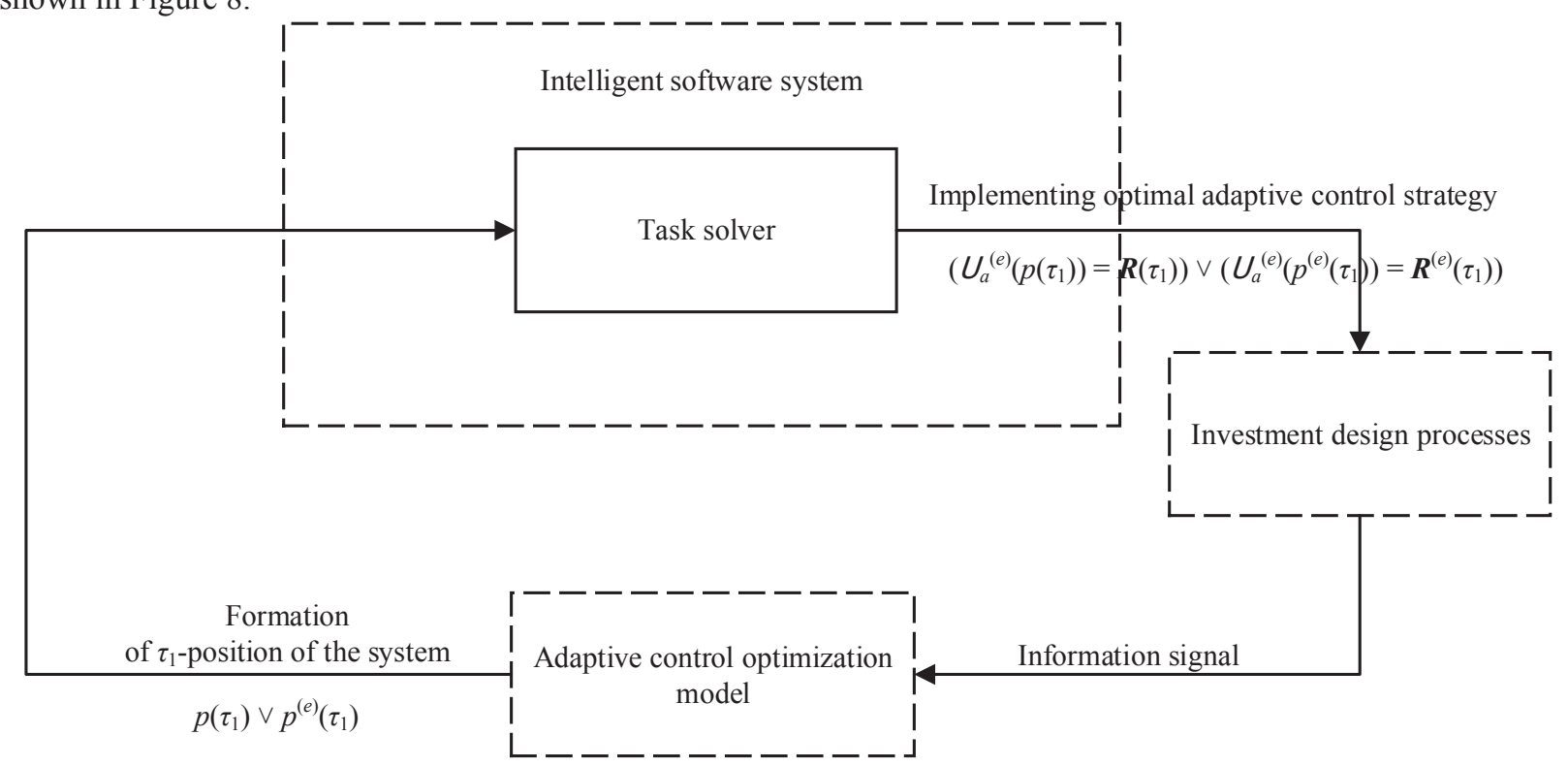

FIGURE 8. Implementation of the optimization adaptive control of investment projecting processes

Note that if you do not apply the proposed method for optimizing adaptive control of investment projecting processes, then in the period of time $T_{0}^{(e)}=8$ equal to the critical time corresponding to the initial calendar schedule, and in which the work-operation $R_{2}\left(\tau_{1}\right)=\widetilde{R}_{2}\left(\tau_{1}\right) \cup \breve{R}_{2}\left(\tau_{1}\right)=\widetilde{R}_{6}(0) \cup \breve{R}_{6}(0)=R_{6}(0)$ of the investment project under consideration has not yet been fully implemented, the project will stop, although in general, it will not be realized yet, which is unacceptable for the investor.

Thus, from the obtained results of solving the model problem of optimizing adaptive control of the implementation of investment projecting processes, we can conclude that the use of the proposed the new method of network formalization and of adaptive project control optimization [1] in the intelligent computer system developed by the authors allows feedback in the form appropriate reactions of the control action to unforeseen changes in situations during the implementation of investment projecting processes and get the optimal result - the optimal time for the implementation of the investment project as a whole.

\section{CONCLUSIONS}

The implementation of investment projecting processes is an important element in the functioning of any financial and economic object, and to solve the complex tasks that arise, it is necessary to develop economic and mathematical models and methods for solving them, as well as create software complexes based on them that automate basic functions and support control decision-making.

This article describes an intelligent computer system that implements optimization of adaptive control of investment projecting processes based on the new method of network formalization and of adaptive project control optimization [1], using network economic and mathematical modeling and computer expert systems technologies. The proposed intelligent software system is implemented in the Delphi environment in the form of a web application and is convenient as a tool for decision support in the implementation of network economic and mathematical modeling and investment projecting processes.

Implementation of the developed intellectual computer system by business entities in the practice of their work will allow them to increase the efficiency of the processes of formation and implementation of investment projects. This system can also be used for quality assessment of developed investment projects and for training. 


\section{ACKNOWLEDGMENTS}

This work was supported by the Russian Basic Research Foundation, project no. 18-01-00544 "Problems of attainability, control, estimation in dynamical systems with impulse control and uncertainty."

\section{REFERENCES}

1. A.F.Shorikov, "Network economic and mathematical model of adaptive project control. Analysis, modeling, control, development of socio-economic systems," in Collection of Materials XIII International School-Symposium AMUR-2019, edited by A.V. Sigal, ISBN 978-5-6042038-4-2 (KFU Publ., Simferopol, 2019), pp. 425-428.

2. A.F. Shorikov, Minimax Estimation and Control in Discrete Dynamical Systems (Publ. Ural State University, Ekaterinburg, 1997), 242p. [in Russian]

3. A.F. Shorikov and E.V. Butsenko, Prediction and Optimization of the Results of Investment Projecting Control (URSSLENAND Publ., Moscow, 2017), 272p. [in Russian]

4. A. Kofman and G. Debazey, Network Planning Methods and Their Application (Progress Publ., Moscow, 1968) 182p. [in Russian]

5. H.A. Taha, Operations Research: An Introduction, 7th edn (Prentice Hall Publ., 2002), 848p.

6. D. Marsellus, Expert Systems Programming in Turbo Prolog (Prentice Hall Inc., NJ, 1989), 266p.

7. V.A. Emelyanov and N.Yu. Emelyanova, "Theoretical foundations of the construction and training of hybrid intelligent systems," in the book Actual Issues of Technical Sciences: Theoretical and Practical Aspects (Ufa, 2016), pp. 54-69.

8. K. Aksyonov, E. Bykov, O. Aksyonova, N. Goncharova, and A. Nevolina, "Application of the hybrid agents technology for control of the construction company, in Proc. of the International Conf. on Computer Science and Applications 2016 (ICCSA 2016) part of the World Congress on Engineering and Computer Science 2016, WCECS 2016, October 19-21, 2016, San Francisco, USA, Vol I, pp. 159-164.

9. K. Aksyonov, E. Bykov, O. Aksyonova, N. Goncharova, and A. Nevolina, "Analysis of simulation modeling systems illustrated with the problem of model projecting for the subject of technological logistics (WIP)," in Society for Modeling \& Simulation International (SCS). 2015 Summer Simulation Multi-Conference (SummerSim'15). Chicago, USA, 26-29 July, 2015, Simulation Series, Vol. 47, Issue 10, 2015, pp. 345-348.

10. K.J. Astroem and B. Wittenmark, Adaptive Control, 2nd edn (Dover Publications, 2008), 590p.

11. I.D. Landau, R. Lozano, M. M'Saad, and A. Karimi, Adaptive Control: Algorithms, Analysis and Applications (Springer, London, 2011), 610p. 